\title{
COMPARISON OF TOP HEIGHT AND DOMINANT HEIGHT WITH TREE VARIABLES AT THE EVEN AGED Pinus caribaea (MORELET) PLANTATION AT YAGIRALA
}

\author{
Kandasami Pirapaharan \& S.M.C.U.P.Subasinghe \\ Department of Forestry and Environment Science, \\ University of Sri Jayewardenepura
}

Top height and dominant heights are confisedly interpret in many countries. The main aim of this study was find the similarity of above two terms and to build some models to predict them.

The study was carried out in Yagirala 25 year old even aged Pinus caribaea plantation. Top height and dominant heights were compared with other tree variables. Stratified random sampling without replacement was used to select the sampling unit. Circular plots of 0.05 hectare with slope correction and boundary adjustment were used to obtain the required tree measurements.

Diameter at breast height, total height, lover and upper crown height were measured and basal area and crown depth were calculatec. Top height and dominant height were also estimated

Results indicated that there is a significant difference between top and dominant heights. Also two separate equations to predict these two heights were developed. According to the results initially ten equations were selected. Five equations described the relationship between top and total height while the other five described the relationship between dominant height and total height. Finally the best two equations were selected using coefficient of variation values and the distributions of standard residuals.

Proceedings of the Eighth Annual Forestry and Environment Symposium 2002 of the Department of Forestry and Environmental Science, University of Sri Jayewardenepura, Sri Lanka 